\title{
Impact Of Strain Rate On Mechanical Properties Of Metallic Sheets At Various Temperatures
}

\author{
Dr BVS Rao' ${ }^{1}$, P. Anjani Devi ${ }^{2}$ \\ 1,2 Assistant Professor ,Mechanical Engineering Department, \\ Chaitanya Bharathi Institute of Technology
}

Article History: Received: 10 January 2021; Revised: 12 February 2021; Accepted: 27 March 2021; Published online: 10 May 2021

\begin{abstract}
It is known that in warm and hot forming processes, the forming speed and with-it combined strain rate has immense role on material flow in bulk and sheet metal operations. In contrast, the influence of the strain rate on the flow curve has been rarely analysed at room temperature. This work analyses the influence of strain rate on flow curve of bimetallic sheets, Copper and Aluminium metals. Evaluation of the flow curve is carried out as a function of strain rate. In this work three different strain rates are considered for three different materials viz bimetallic sheets $(\mathrm{Cu}-\mathrm{Al})$, Copper and Aluminium. In addition to this ,the evaluation of flow curve at elevated temperatures is carried out. The Variation of mechanical properties with strain rate are plotted and analysed.
\end{abstract}

Keywords: strain rate, bimetallic strip ,Flow curve.

\section{Introduction :}

Often materials are subjected to external force when they are used. Mechanical Engineers calculate these forces and material scientists investigate how materials deform or break as a function of force, time, temperature, and other conditions. Materials scientists learn about these mechanical properties by testing various materials and evaluating the mechanical properties like Brittleness, Creep, Ductility, Elasticity, Fatigue, Hardness, Malleability, Stiffness, Yield strength. Heating the metal will displace atoms from their position and the displaced atoms form a new structure.

The earliest surviving bimetallic strip was made by the eighteenth-century clockmaker John Harrison who is generally credited with its invention. He made it for his third marine chronometer (H3) of 1759 to compensate for temperature-induced changes in the balance spring. It should not be confused with the bimetallic mechanism for correcting for thermal expansion in his Giridon Pendulum. His earliest examples had two individual metal strips joined by rivets but he also invented the later technique of directly fusing molten brass onto a steel substrate. A strip of this type was fitted to his last timekeeper, H5. Harrison's invention is recognized in the memorial to him in Westminister Abbey, England.

Bimetal refers to an object that is composed of two separate metals joined together. Instead of being a mixture of two or more metals, like alloys, bimetallic objects consist of layers of different metals. Trimetal and tetrametal refer to objects composed of three and four separate metals respectively. A bimetallic sheet is usually made of combinations of Copper-Aluminium, steel-Copper. It is achieved by cladding, roll bonding, explosive welding.

S. Nagarjuna and M. Srinivas ${ }^{[1]}$ investigated the high temperature tensile properties of $\mathrm{Cu}-1.5 \mathrm{wt} . \% \mathrm{Ti}$ alloy in the temperature range of $100-550{ }^{\circ} \mathrm{C}$. Substantial increase in yield and tensile strengths of solution treated alloy is observed with increasing temperature, with a peak at $450{ }^{\circ} \mathrm{C}$ and decrease in strength beyond this temperature. $\mathrm{Cu}-\mathrm{Ti}$ alloys have been developed with the aim of substituting them for the toxic and expensive $\mathrm{Cu}-$ Be alloys. It reports the results obtained on high temperature tensile properties of a $\mathrm{Cu}-1.5 \mathrm{wt}$. \% $\mathrm{Ti}$ alloy in solution treated (ST) and peak aged (PA) conditions. Radovic et al ${ }^{[2]}$ investigated that the tensile response of Ti3SiC2 is a strong function of strain rate and temperature. Increase in testing temperature and decrease in testing strain rate leads to large tensile plastic deformations. The high value of strain rate sensitivity $(0.42$ to 0.56$)$ of Ti3SiC2 was obtained from tensile tests and confirmed by strain rate jump/drop test and stress jump creep tests. That value is equal to or greater than the strain rate sensitivity of most superplastic ceramics. The deformation of fine-grained Ti3SiC2 also has another aspect in common with superplastic ceramics -- significantly larger elongation to failure that are typically observed in ceramics. The large elongation to failure appears to result from a high degree of damage, not from a structure that remains self-similar throughout deformation.J. O noroa et al. ${ }^{[3]}$ studied The mechanical properties of particulate-reinforced metal-matrix composites based on aluminium alloys (6061 and 7015) at high temperatures . Boron carbide particles were used as reinforcement. All composites were produced by hot extrusion. The tensile properties and fracture analysis of these materials were investigated at room temperature and at high temperature to determine their ultimate strength and strain to failure. Rao, K.P.et al ${ }^{[4]}$ suggested that an understanding of the plastic behaviour of various metals and alloys is necessary for their successful forming. Flow curves facilitate understanding of the plastic behaviour of materials. The determination of the flow curves at different temperatures and strain rates is equally important for both the researcher and the production engineer. The different test methods used for determining the flow curves, together with their relative merits and demerits and the influencing parameters, are discussed.

\section{Methodology:}

\subsection{Experimental procedure for bimetallic strip at room temperature}

The bimetallic strip that is used for testing is obtained by roll bonding process-the combination of bimetallic strip is Copper on one side and Aluminium on other side. The bimetallic sheet is cut according to the ASTM E8 
standard using milling machine. A total of 3 specimen are cut for testing at three different strain rates. The edges of the specimen are rubbed with emery paper to keep the edges smooth for gripping. The specimen is then fixed in NANO UTM and tested at three different feed rates viz,. $5 \mathrm{~mm} / \mathrm{min}, 10 \mathrm{~mm} / \mathrm{min}$ and $15 \mathrm{~mm} / \mathrm{min}$. The final tests were performed at SUNRAY laboratories Nacharam.

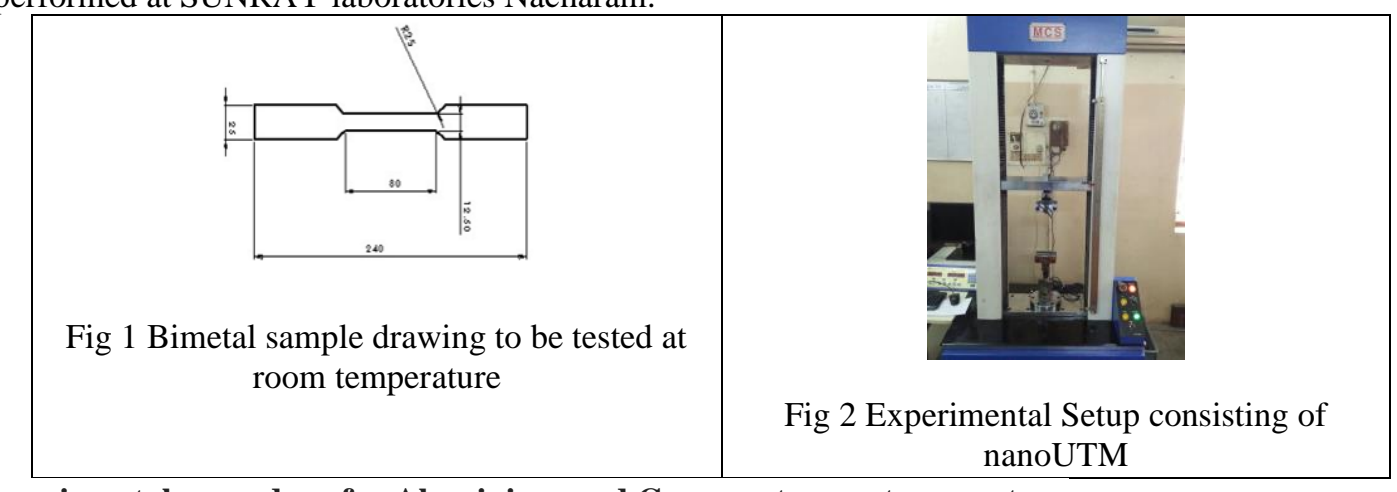

2.2 Experimental procedure for Aluminium and Copper at room temperature

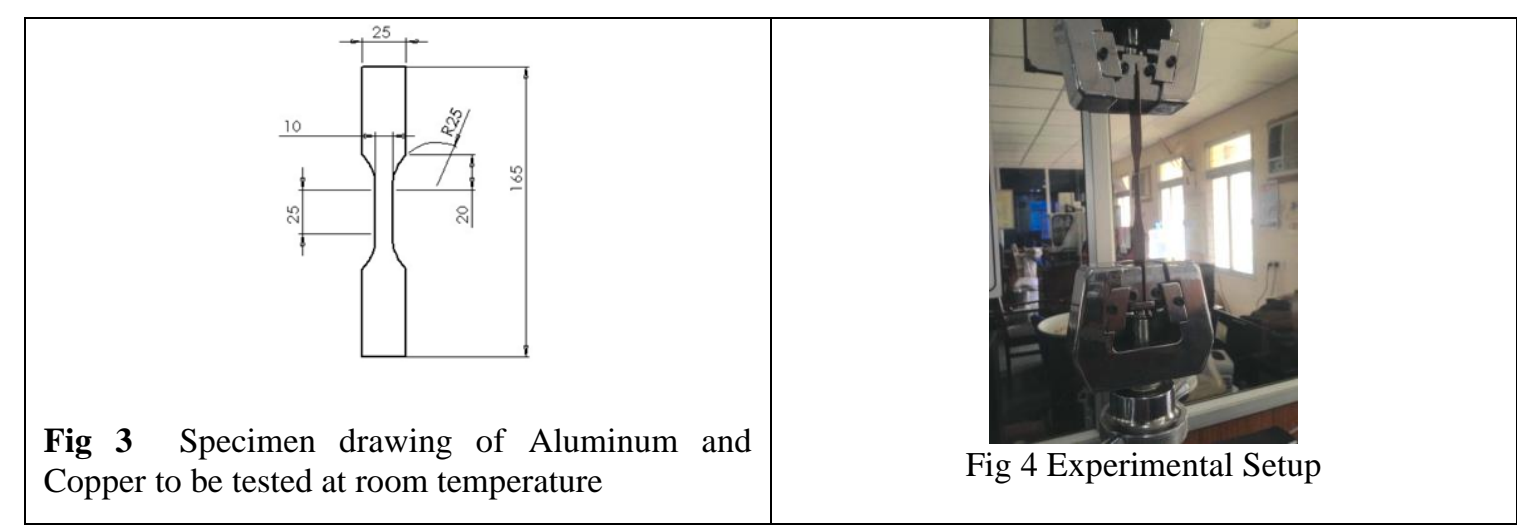

Firstly, the bimetallic sheet is cut according to the ASTM E8 standard using milling machine. A total of 6(3 Aluminium and 3 Copper) specimens are cut for testing under 3 different strain rates. Then the edges of the specimen are rubbed with emery paper to keep the edges smooth for gripping. Then the specimen is tested using NANO UTM at feedrates of $0.5 \mathrm{~mm} / \mathrm{min}, 2.5 \mathrm{~mm} / \mathrm{min}$ and $5 \mathrm{~mm} / \mathrm{min}$ and the results are noted. Fig $1 \& 3$ are the specimen drawing of Aluminium and Copper to be tested at room temperature .Fig 3 \& 4 consists of experimental setup.

\subsection{Experimental procedure for bimetallic strip at elevated temperatures}

The bimetallic strip that is used for testing is obtained by roll bonding process and is the combination of Copper on one side and Aluminium on other side. The bimetallic sheet is cut according to the ASTM E8 with a milling machine. A total of 3 specimen are cut for testing under 3 different strain rates. The edges of the specimen are rubbed with emery paper to keep the edges smooth for gripping. The specimen is then fixed in NANO UTM and a feed rate of $0.5 \mathrm{~mm} / \mathrm{min}$ is applied and the test is carried out. Similarly, the test is carried out with two feed rates of $5 \mathrm{~mm} / \mathrm{min}$ and $50 \mathrm{~mm} / \mathrm{min}$. This specimen drawing shows the drawing of bimetal sample to be performed at elevated temperature.

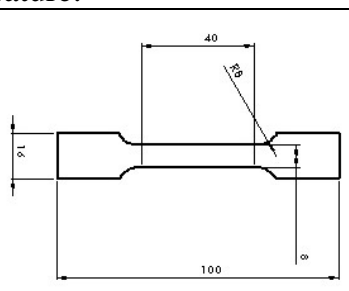

Fig 5 Bimetal sample to be tested at room temperature.

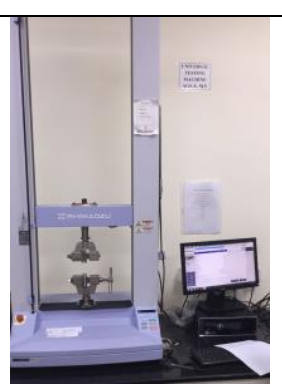

Fig 6 Experimental Setup

\section{Results \& Discussions:}

3.1 For Bimetals at room temperature 


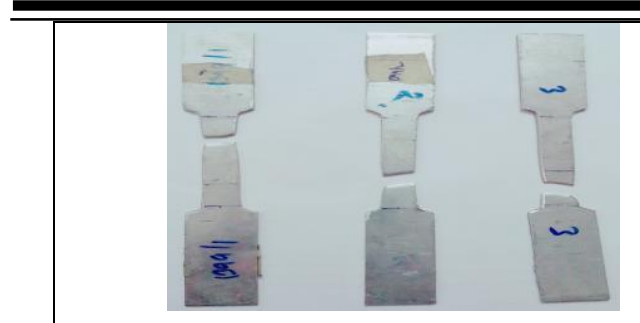

Fig 7 Bimetal Samples after testing

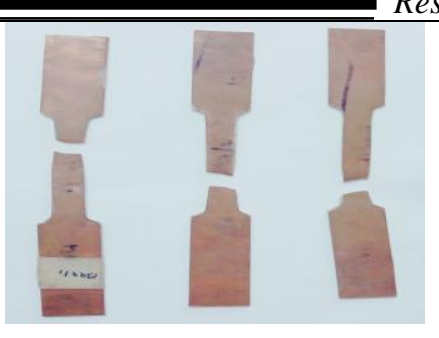

Fig 8 Bimetal Samples after testing

Figure 7 and 8 _ shows the work samples of bimetals after testing at room temperature.

Table 1 Strain rate vs Mechanical properties of bimetals

\begin{tabular}{|c|c|c|c|c|c|}
\hline S.No & $\begin{array}{c}\text { Strain } \\
\text { rate(mm/min) }\end{array}$ & $\begin{array}{c}\text { Yield Point } \\
\text { Strength(MPa) }\end{array}$ & $\begin{array}{c}\text { Ultimate } \\
\text { Tensile } \\
\text { Strength(MPa) }\end{array}$ & \%longation & $\begin{array}{c}0.2 \% \\
\text { Proof } \\
\text { load(KN) }\end{array}$ \\
\hline 1 & 5 & 142.824 & 146.351 & 12.88 & 3.561 \\
\hline 2 & 10 & 151.165 & 153.279 & 11.300 & 3.688 \\
\hline 3 & 15 & 151.11 & 154.61 & 11.22 & 3.596 \\
\hline
\end{tabular}

Table1 shows the data of mechanical properties of bimetals at room temperature at various strain rates of $5,10,15 \mathrm{~mm} / \mathrm{min}$.

From the data, corresponding graphs are drawn which include Strain rate vs Yield Point Strength, Strain rate vs Ultimate Tensile Strength ,Strain rate vs\% Elongation and Strain rate vs 0.2\% Proof load.

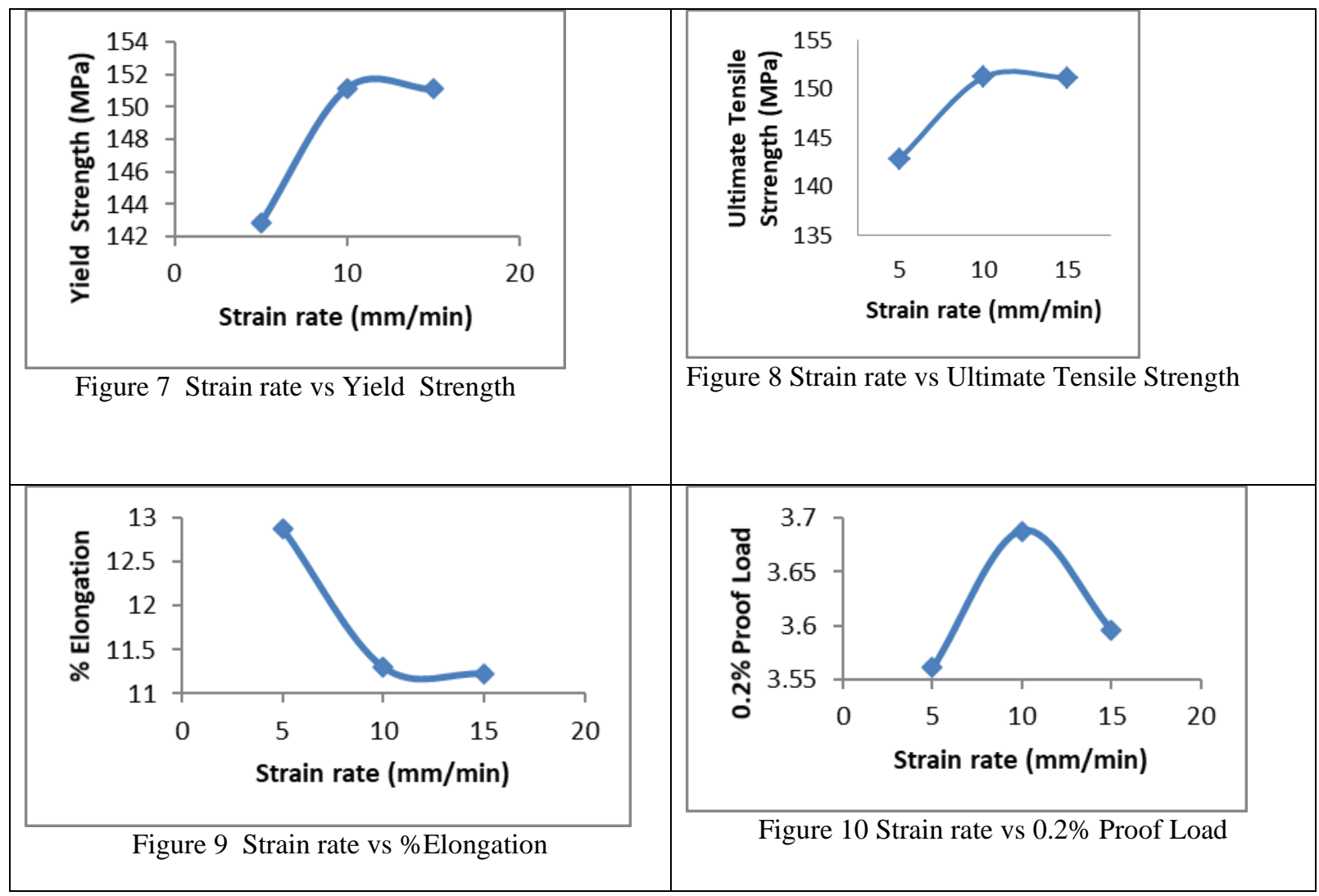


Fig 7 shows the variation of Yield Strength for different strain rates and it is observed that the Yield Point Strength found to increase with increase in strain rate. Fig 8 shows the variation of Ultimate Tensile Strength for different strain rates and it is observed that the Ultimate Tensile Strength increases with increase in strain rate.Fig 9 shows the variation of \% Elongation for different strain rates and it is observed that the \% Elongation decreases with increase in strain rate. Fig 10 is the variation of $0.2 \%$ Proof Load for different strain rates and it is observed that $0.2 \%$ Proof load increases with increase in strain rate.

\subsection{For Copper \& Aluminum at room temperature}

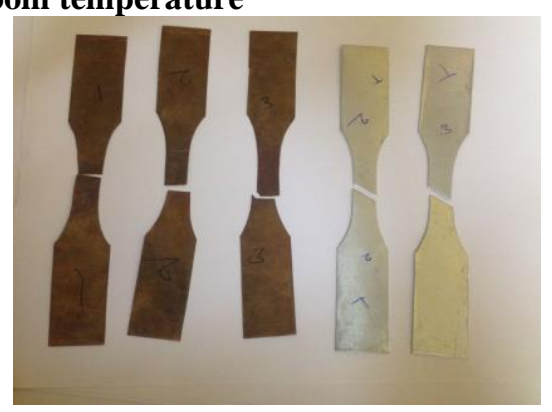

Fig.11 Aluminum \& Copper samples after testing

Figure 11 shows the work samples of Aluminiun and Copper after testing at room temperature. The Mechanical properties following after tensile testing of Aluminium are tabulated below.

\section{Table 2 Strain rate vs Mechanical properties of Aluminium}

\begin{tabular}{|c|c|c|c|}
\hline S.No & Strain rate $(\mathrm{mm} / \mathrm{min})$ & Ultimate Tensile Strength $(\mathrm{MPa})$ & $0.2 \%$ Proof Load $(\mathrm{KN})$ \\
\hline 1 & 0.5 & 150.707 & 1.718 \\
\hline 2 & 2.5 & 151 & 1.469 \\
\hline 3 & 5 & 155 & 1.518 \\
\hline
\end{tabular}

Table 2 shows the variation of mechanical properties of (Ultimate Tensile strength \& $0.2 \%$ Proof Load ) aluminium at the strain rates of $0.5,2.5,5 \mathrm{~mm} / \mathrm{min}$.

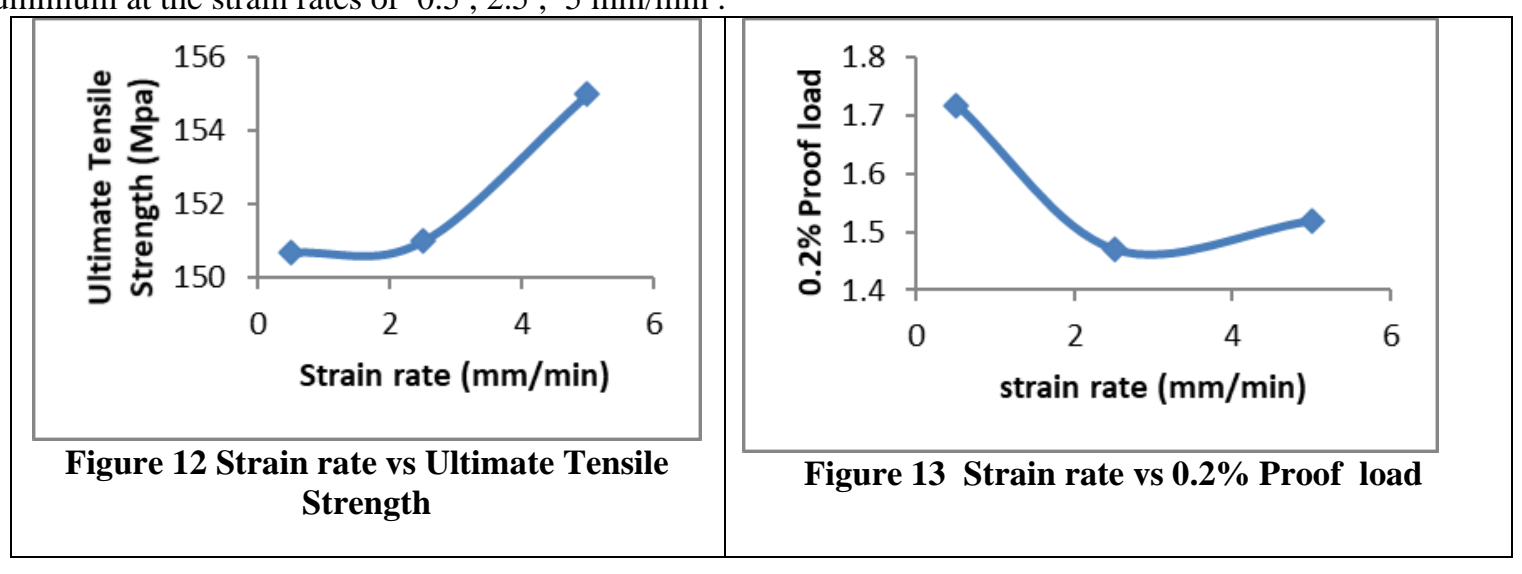

Fig 12 and 13 show the variation of Ultimate Tensile Strength and $0.2 \%$ Proof Load for different strain rates and it is observed that the $0.2 \%$ Proof Load found to decrease first and then increase with increase in strain rate.

Table 3 Strain rate vs Mechanical properties of copper

\begin{tabular}{|c|c|c|c|}
\hline S.No & $\begin{array}{c}\text { Strain rate } \\
(\mathrm{mm} / \mathrm{min})\end{array}$ & $\begin{array}{c}\text { Ultimate Tensile Strength } \\
(\mathrm{MPa})\end{array}$ & $0.2 \%$ Proof Load (KN) \\
\hline 1 & 0.5 & 220 & 1.412 \\
\hline 2 & 2.5 & 239 & 1.428 \\
\hline 3 & 5 & 240 & 1.304 \\
\hline
\end{tabular}




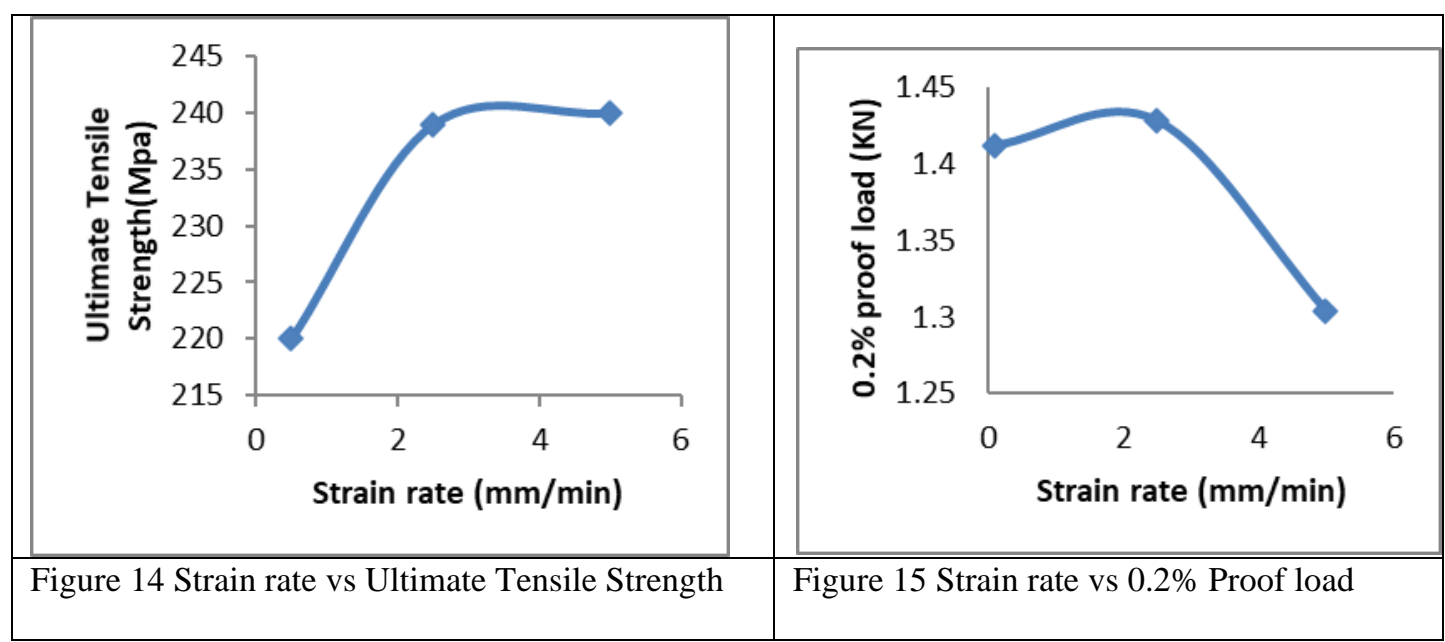

Fig 14 shows the variation of Ultimate Tensile Strength for different strain rates and it is observed that the Ultimate Tensile Strength found to increase with increase in strain rate .Figure 15 shows the 0.2\% Proof Load for different Strain rates for copper material

\subsection{For Bimetals at elevated temperatures}

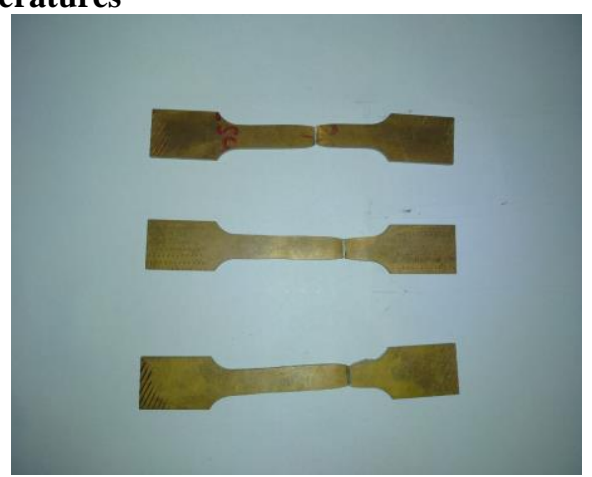

Figure 16 Bimetal samples after testing

Figure 16 shows the work samples of bimetals after testing at elevated temperatures.

Table 4: Strain rate vs Mechanical properties of bimetals at elevated temperatures

\begin{tabular}{|c|c|c|c|c|c|c|c|c|c|c|c|}
\hline \multirow{2}{*}{$\begin{array}{l}\text { SL } \\
\text { NO }\end{array}$} & \multirow{2}{*}{$\begin{array}{c}\text { TEST } \\
\text { PARAMETER }\end{array}$} & \multirow[t]{2}{*}{ UNITS } & \multicolumn{9}{|c|}{ RESULTS } \\
\hline & & & \multicolumn{3}{|c|}{$150^{\circ} \mathrm{C}$} & \multicolumn{3}{|c|}{$200^{\circ} \mathrm{C}$} & \multicolumn{3}{|c|}{$250^{\circ} \mathrm{C}$} \\
\hline & Strain Rate $(\mathrm{mm}$ & & 0.5 & 5 & 50 & 0.5 & 5 & 50 & 0.5 & 5 & 50 \\
\hline 1 & Tensile Strength & MPa & 130.2 & 131.6 & 140.1 & 116.0 & 116.7 & 118.8 & 97.3 & 100.8 & 102.8 \\
\hline 2 & \% Elongation & $\%$ & 167 & 162 & 151 & 27 & 20 & 100 & 265 & 254 & 252 \\
\hline
\end{tabular}

Table 4 shows the variation of mechanical properties like Tensile strength and \% elongation at different temperatures of $150^{\circ} \mathrm{C}, 200^{\circ} \mathrm{C}, 250^{\circ} \mathrm{C}$.

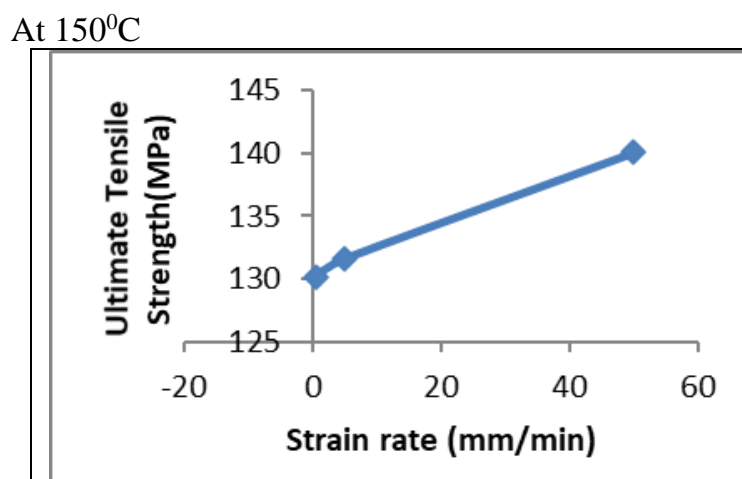

Figure 17 Strain rate vs Ultimate Tensile Strength

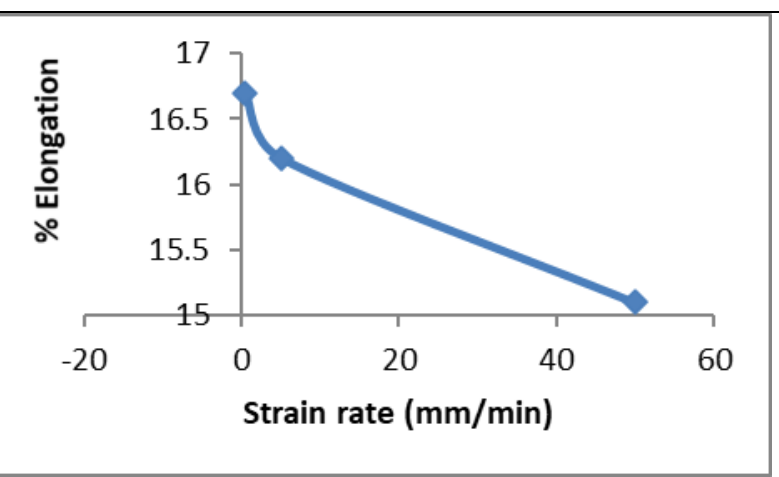

Figure 18 Strain rate vs \% Elongation

Figure 17 shows the variation of Ultimate Tensile Strength for different strain rates at an elevated temperature of $150^{\circ} \mathrm{C}$ and it is observed that the Ultimate Tensile Strength increase with increase in strain rate and temperature. 
Fig 18 is the variation of $\%$ Elongation for different strain rates at $150^{\circ} \mathrm{C}$ and it is observed that the $\%$ Elongation found to decrease with increase in strain rate and temperature.

At $200^{\circ} \mathrm{C}$

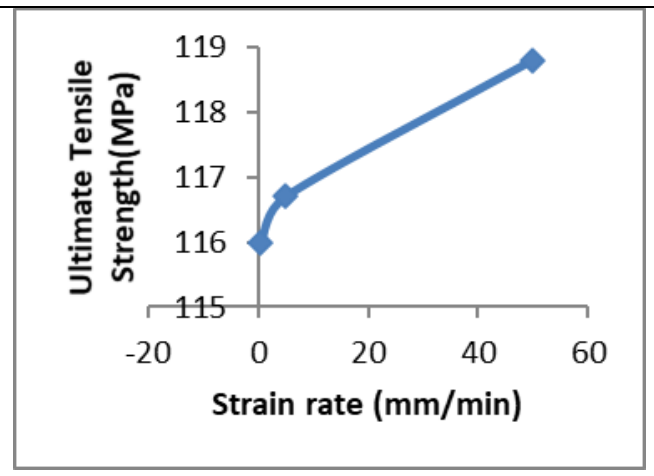

Figure 19 Strain rate vs Ultimate Tensile Strength

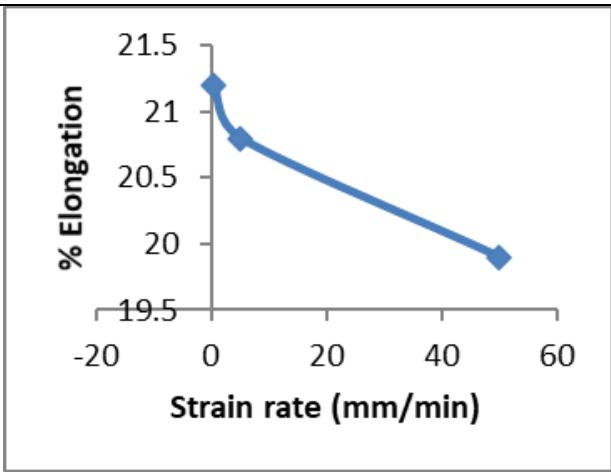

Figure 20 Strain rate vs \% Elongation

Figure 19 shows the variation of Ultimate Tensile Strength for different strain rates at $200^{\circ} \mathrm{C}$ and it is observed that the Ultimate Tensile Strength found to increase with increase in strain rate and temperature. Figure 20 is the variation of \% Elongation for different strain rates for elevated temperatures and it is observed that the \% Elongation found to decrease with increase in strain rate and temperature.

\section{At $250^{\circ} \mathrm{c}$}

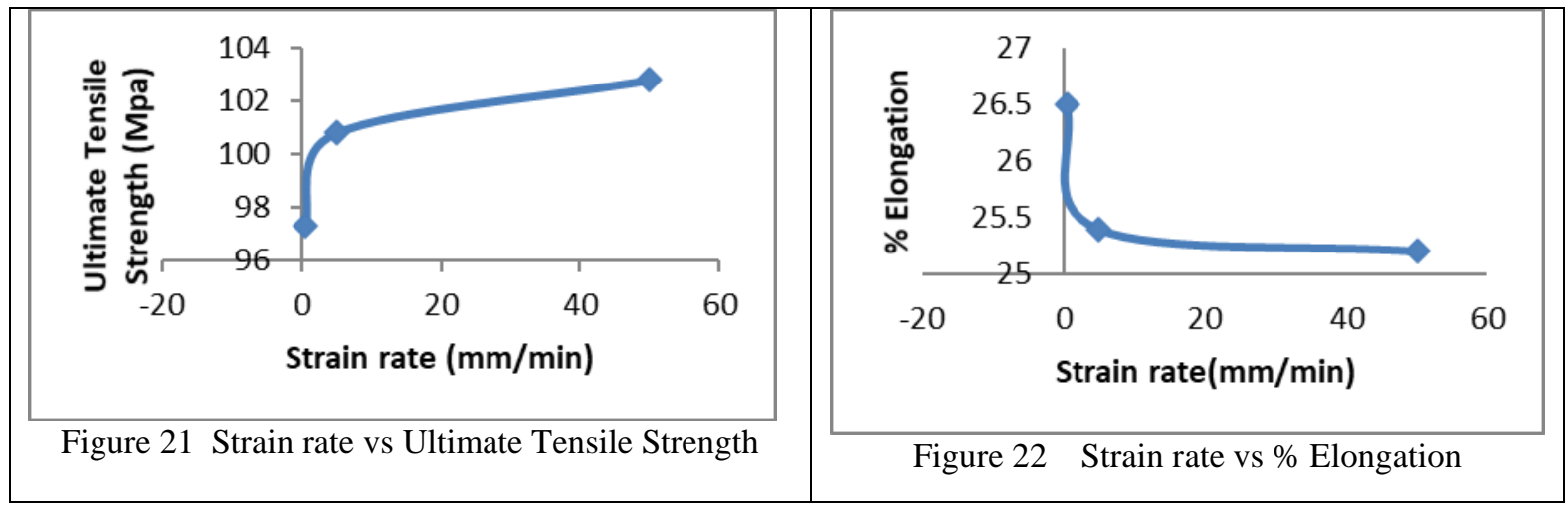

Fig 21 shows the variation of Ultimate Tensile Strength for different strain rates for elevated temperatures of $250^{\circ} \mathrm{C}$ and it is observed that the Ultimate Tensile Strength increase with increase in strain rate and temperature. Fig 22 shows the variation of \% Elongation for different strain rates for elevated temperatures and it is observed that the $\%$ Elongation decrease with increase in strain rate and temperature

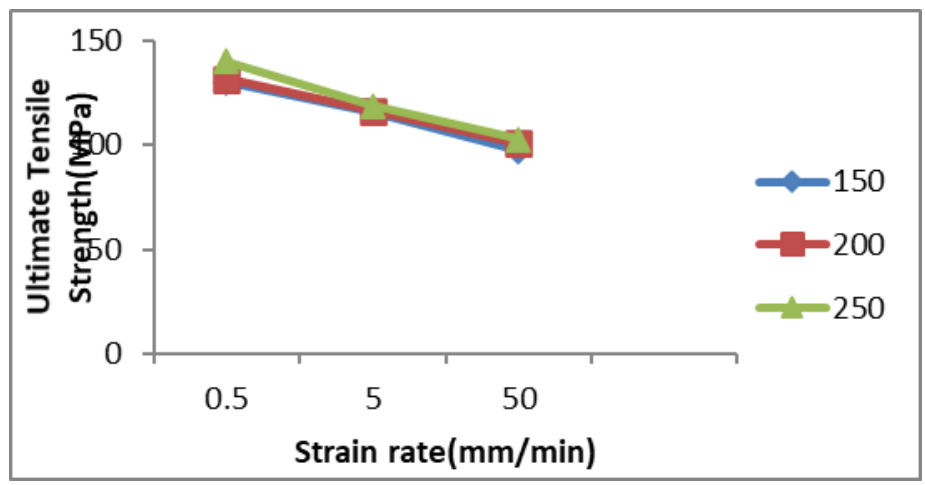

Figure 23 Variation of Ultimate Tensile Strength for different strain rates at different temperatures

Fig 23 shows the comparison of variation of Ultimate Tensile Strength and strain rate at different temperatures viz. $150^{\circ} \mathrm{C}, 200^{\circ} \mathrm{C}$ and $250^{\circ} \mathrm{C}$.

\section{Conclusion}

- With increase in strain rate the mechanical properties like yield point and ultimate tensile strength are found to increase. 
- With increase in strain rate, \% elongation and yield load moderately decrease.

- As temperature varies ,it is evident that the properties of materials change at high rate i.e., with increase in temp and strain rate, the yield point and ultimate tensile strength goes on decreasing.

- At room temperature, variation in mechanical properties seem to be less significant.

\section{Future scope:}

- Using the above results cylindrical cups can be drawn at different strain rates and also the microscopic structure of these drawn cups can be evaluated.

- Also for metals like Titanium, Invar, Trimetallic, the above tests can be performed.

\section{References}

1. S. Nagarjuna and M. Srinivas High temperature tensile behaviour of a $\mathrm{Cu}-1.5$ wt.\% Ti alloy Defence Metallurgical Research Laboratory, Defence Research and Development Org. (2001).

2. M. Radovic M. W. BarsoumT. El-Raghy J. Seidensticker and S. Wiederhorn Tensile properties of $\mathrm{Ti}_{3} \mathrm{SiC}_{2}$ in the $25-1300^{\circ} \mathrm{C}$ temperature range.

3. J.Oñoroa M.D.Salvadorb and L.E.G.Cambronero, "High-temperature mechanical properties of aluminium alloys reinforced with boron carbide particles", Materials Science and Engineering: A , Volume 499, Issues 1-2, 15 January 2009, Pages 421-426

4. Rao, K.P., Doraivelu, S.M. (1982): Flow curve and deformation of materials at different temperatures and strain rates. Journal of mechanical working technology; Vol. 6.

5. T Pepelnjak and S Smoljanic " The impact of strain rate on sheet metal formability at room temperature", RMZ-M\&G 60, 3-8,2013

6. A text book of Mechanical Metallurgy by George E. Dieter.

7. J Zener C, Hollomon J H High speed testing of mild steel Am. Soc. Metals, in print

8. ZENER, C., HOLLOMAN, J.H.-Plastic flow and rupture in metals, Trans. Amer. Soc. Metals, Vol. 33, 1944, pp. 163-215. J. H. Hollomon and C. Zener, "Conditions for fracture of steel," Am. Inst. Min. Met. Eng.

9. C. Zener and J. H. Hollomon, Effect of Strain Rate Upon Plastic Flow of Steel, Journal of Applied Physics 15, 22 (1944) 